\title{
Diagnostic difficulties by the unusual presentations in children and adolescents with Hashimoto thyroiditis
}

Betül Ersoy, MD', Kiremitçi Yılmaz Seniha, MD', Deniz Kızılay, MD', Münevver Yılmaz, MD², Şenol Coşkun, MD²

${ }^{1}$ Division of Pediatric Endocrinology, Department of Pediatrics, School of Medicine, Celal Bayar University, Manisa, ${ }^{2}$ Division of Pediatric Cardiology, Department of Pediatrics, School of Medicine, Celal Bayar University, Manisa, Turkey
Received: 20 June, 2016

Revised: 6 August, 2016

Accepted: 21 September, 2016

Address for correspondence: Seniha Kiremitçi Yılmaz

Division of Pediatric Endocrinology, Department of Pediatrics, School of Medicine, Celal Bayar University, Manisa, Turkey

Tel: +905064568872

Fax: +903423600290

E-mail: skyilmaz.dr@gmail.com
Complex clinical presentation with diverse timing of particular symptoms may cause diagnostic difficulties, especially in children and adolescents. This paper presents diagnostic difficulties and pitfalls in 3 children with acquired primary hypothyroidism due to Hashimoto's thyroiditis (HT) presenting with unusual manifestations. We described 3 children with acquired primary hypothyroidism due to HT. One of our patients had musculoskeletal pain and was diagnosed and treated as having connective tissue disease. Another patient presented with chest pain, dyspnea, and swelling in the abdomen. She had a massive pericardial effusion (PE). Two patients had severe growth failure. A third patient with Down syndrome had a small PE. Her complaint was dyspnea during sleep. All patients improved with thyroxin therapy. Patients with hypothyroidism due to HT who have complicated clinical manifestations were misdiagnosed and mismanaged at childhood and adolescence. Growth failure is an important sign in children and adolescents. In the presence of complicated manifestations in children and adolescents, thyroid dysfunction must be considered in differential diagnosis.

Keywords: Hypothyroidism, Children, Musculoskeletal pain, Pericardial effusion, Hashimoto thyroiditis

\section{Introduction}

Hashimoto thyroiditis (HT) is one of the most common autoimmune endocrine diseases in pediatric age groups ${ }^{1)}$. Patients with HT can present different thyroid function patterns ranging from a transient hyperthyroidism to frank hypothyroidism. Most patients with HT are clinically euthyroid, some patients are hypothyroid, and a few are hyperthyroid. Consequently, the clinical course of HT is variable ${ }^{1,2)}$.

Most systemic manifestations in patients with HT originate from loss of function of the thyroid gland and subsequent primary hypothyroidism ${ }^{3)}$. Varying clinical manifestations related to organ hypofunction (e.g., cardiac, hepatic, skin, renal) occur with prolonged or severe hypothyroidism ${ }^{3}$. For this reason, patients may initially be referred to cardiologists, rheumatologists, or dermatologists before being referred to an endocrinologist. On the other hand, pericardial effusion (PE) is the most common cardiac manifestation of hypothyroidism in adults ${ }^{4}$. Rheumatic or musculoskeletal symptoms may be the initial presentation of hypothyroidism at adulthood ${ }^{5,6)}$. However, these findings appear to be a rare in children and adolescents ${ }^{4}$.

Here, we present diagnostic difficulties and pitfalls in 3 children and adolescents with hypothyroidism due to HT presenting with unusual manifestations.

The authors obtained written informed consent from the patients of parents for publication. 


\section{Case reports}

\section{Case 1}

A 10-years-old girl presented with complaints of muscle pain, malaise, coldness in the hands and feet, color changes in her finger in response to cold, and bruising after blanching. Previous medical history revealed no trauma, vigorous exercise, infection, or any medication usage. On physical examination, her height was $124 \mathrm{~cm}(-2.7$ standard deviation [SD]), and her weight was $27 \mathrm{~kg}(-1.2 \mathrm{SD})$. She had severe short stature. Her bone age was 8 years. She had normal heart rate $(84 / \mathrm{min})$, respiratory rate (30/min), and, blood pressure $(95 / 50 \mathrm{mmHg})$. Her skin showed diffuse dryness. Coldness in the hands and feet, nonpitting leg edema, and periorbital edema were present. Neurological

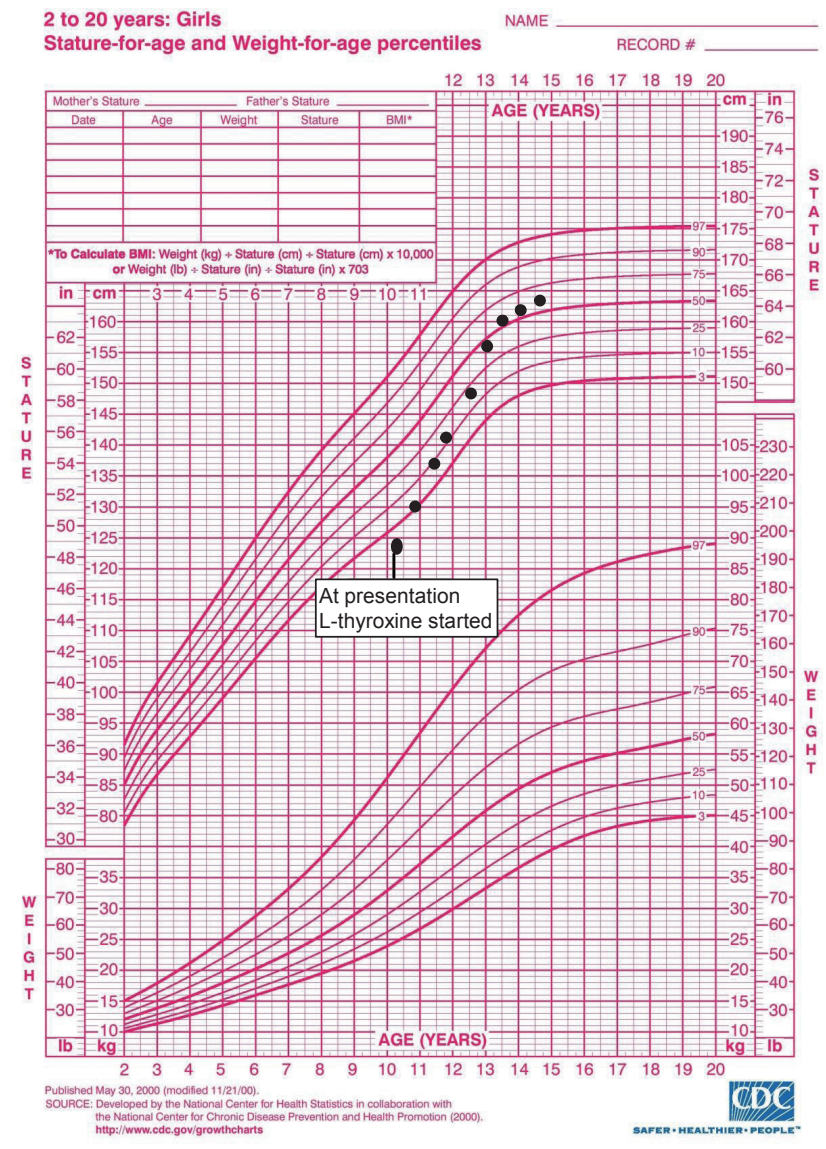

Fig. 1. Growth chart of case 1. examination showed weakness of proximal muscles of both upper and lower extremities. She had no sign of joint swelling or arthritis and had normal range of motion of all joints.

A pediatric rheumatologist had performed initial laboratory evaluations and found elevated levels of creatine kinase (CK) (2,039 U/L). A normal electromyogram had been obtained. It had been thought to be systemic sclerosis (SS) among connective tissue disease (CTD). Prolonged gastric emptying time supported this diagnosis. Although, rheumatologic markers, including antinuclear antibody, anti-double-stranded DNA, antineutrophilic cytoplasmic antibody, cytoplasmic, and antiextractable nuclear antigen (anti-Ro, anti-La, anti-Sm, anti-RNP, anti-Scl-70, anti-Jo-1), were all negative, a pediatric rheumatologist started the patient on naproxen and a calcium channel blocker. The patient had no improvement. When it was realized that she had goiter, the patient was sent to a pediatric endocrinologist.

In the thyroid function test, thyroid stimulating hormone (TSH) was elevated (>100 $\mu \mathrm{IU} / \mathrm{mL}$; normal range, $0.35-5 \mu \mathrm{U} /$ $\mathrm{mL})$, and fT4 was decreased $(<0.25 \mathrm{ng} / \mathrm{dL}$; normal range, $0.8-2$ $\mathrm{ng} / \mathrm{dL}$ ). Thyroid-peroxidase antibodies (anti-TPO) were present in high titers $(201 \mathrm{IU} / \mathrm{mL}$ ). Thyroid ultrasonography (USG) was consistent with thyroiditis. These findings were also consistent with the diagnosis of autoimmune thyroiditis or HT with associated hypothyroidism. After treatment with L-thyroxine, her muscle strength gradually improved, other clinical symptoms regressed, thyroid function tests, CK levels returned to normal within a few weeks. Thyroid function test were presented in Table 1. Her height progressively increased, after 3 years of L-thyroxine treatment she gained 2.9 SD of height and she attained midparental height percentile (Fig. 1). Bone age was appropriate with chronological age.

\section{Case 2}

A 17-year-old female patient was admitted due to cough, chest pain, dyspnea, and swelling in the abdomen. On physical examination, height was $140 \mathrm{~cm}(-3.5 \mathrm{SD})$, and weight was $43 \mathrm{~kg}$ $(-2$ SD). She had severe short stature and 2 years retarded bone age. She was pale and somnolent. Her score on the Glasgow Coma Scale was 11 points. She was dyspneic and cyanotic. Oxygen saturation was $65 \%$, respiratory rate was $24 / \mathrm{min}$, and pulse rate was $120 / \mathrm{min}$. She had hypotension $(80 / 60 \mathrm{mmHg})$ and subfebrile fever $\left(37.4^{\circ} \mathrm{C}\right)$. Her mucous membranes were dry. She had dry skin, sparse hair, and goiter. Cardiovascular examination revealed deep heart sounds. A chest X-ray showed

Table 1. Changes in thyroid function tests with L-thyroxine treatment

\begin{tabular}{|c|c|c|c|c|}
\hline \multirow{2}{*}{ Case } & \multicolumn{2}{|c|}{ Free T4 (ng/dL) } & \multicolumn{2}{|c|}{ TSH $(\mu \mathrm{IU} / \mathrm{mL})^{\mathrm{b})}$} \\
\hline & Before LT4 therapy & After LT4 therapy & Before LT4 therapy & After LT4 therapy \\
\hline 1 & $<0.25$ & 1.6 & $>100$ & 3 \\
\hline 2 & $<0.25$ & 1.1 & $>100$ & 2.7 \\
\hline 3 & $<0.25$ & 1.3 & $>100$ & 2 \\
\hline
\end{tabular}

Free T4, free thyroxine; TSH, thyroid stimulating hormone; LT4, levothyroxine.

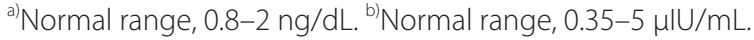


a "tents heart" (Fig. 2). On echocardiography, a massive PE was found. She was taken to undergo urgent pericardiocentesis, removing $1,000 \mathrm{~mL}$ of fluid. Blood investigations, including complete blood count, erythrocyte sedimentation rate, and serologic markers of viral pathogens and autoimmune diseases, were within normal limits. All work up of the fluid for the etiology of the PE was normal. Although pericardiocentesis was performed, hypotension did not recover. Thyroid function analysis showed raised TSH ( $>100 \mu \mathrm{U} / \mathrm{mL}$; normal range, $0.35-5$ $\mu \mathrm{U} / \mathrm{mL})$, decreased fT3 $(0.9 \mathrm{pg} / \mathrm{mL}$; normal range $2.3-5 \mathrm{pg} /$ $\mathrm{mL})$, and decreased fT4 ( $<0.25 \mathrm{ng} / \mathrm{dL}$; normal range, $0.8-2 \mathrm{ng} /$ $\mathrm{dL})$ (Table 1). Antithyroglobulin antibody $(87 \mathrm{IU} / \mathrm{mL})$ and anti-TPO $(860 \mathrm{IU} / \mathrm{mL})$ were positive. Thyroid USG showed thyroiditis. After thyroid replacement therapy was started with an oral formulation, because intravenous thyroxine was unavailable in our country, hypotension and other complaints were resolved. We were unable to follow up her, because she did not apply to our outpatient clinic.

\section{Case 3}

A 17-year-old female diagnosed with Down syndrome applied to pediatric cardiology outpatient clinic with swelling around the eyes and hands and dyspnea during sleep. Her height was $143 \mathrm{~cm}$ (25th-50th percentile according to growth chart for girls with Down syndrome), and her weight was $50 \mathrm{~kg}$ (25th-50th percentile according to growth chart for girls with Down syndrome). Bone age was 16 years. She had normal heart rate $(76 / \mathrm{min})$, respiratory rate $(20 / \mathrm{min})$, blood pressure $(100 / 65 \mathrm{mmHg})$, and body temperature $\left(36.8^{\circ} \mathrm{C}\right)$. Down syndrome stigmata (nasal eccentricity, simian line) were available on physical examination. Echocardiography revealed a PE exceeding $1 \mathrm{~cm}$ (Fig. 3). On laboratory evaluation, TSH was elevated ( $>100 \mu \mathrm{U} / \mathrm{mL}$; normal range, $0.35-5 \mu \mathrm{U} / \mathrm{mL}$ ), and fT4 was decreased $(<0.25 \mathrm{ng} / \mathrm{dL}$; normal range, $0.8-2 \mathrm{ng} / \mathrm{dL})$. Thyroid autoantibodies were positive. After L-thyroxine therapy, facial edema and PE regressed within 15 days. fT4 and TSH levels before and after treatment were shown in Table 1. She grew in accordance with growth curves for children with Down syndrome.

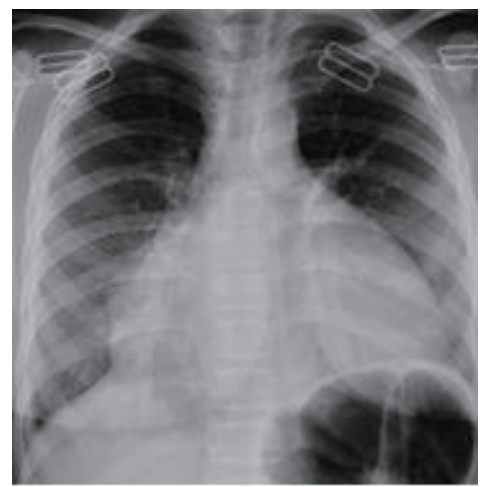

Fig. 2. X-ray examination of case 2 at presentation.

\section{Discussion}

Although euthyroidism is the most common state at HT presentation, the risk of developing overt hypothyroidism is higher in childhood. Thyroid functions of our patients reflected severe hypothyroidism. Patients with hypothyroidism due to HT show a wide variety of clinical presentations, including PE, rheumatic symptoms, musculoskeletal disease, and myxedema coma $^{1)}$. Two of our patients reported to the pediatric cardiology division of the hospital for cardiac complaints, and the other one, with musculoskeletal complaints, reported to the pediatric rheumatology division. These patients were not considered to have hypothyroidism.

Hypothyroidism may cause signs and symptoms of musculoskeletal dysfunction ${ }^{7}$. Patients with hypothyroidism had complaints suggestive of muscle dysfunction, such as weakness, fatigability, muscle pain, stiffness, or cramps. These symptoms are thought to be related to prolonged hypothyroidism. But musculoskeletal signs and symptoms occur in most newly diagnosed patients with thyroid disease ${ }^{5}$. In the presence of these signs and symptoms, hypothyroid patients have been misdiagnosed and mismanaged as suffering from CTD, as in case 1 . SS was diagnosed in case 1, and a rheumatologist initiated treatment before the patient was referred to Pediatric Endocrinology. However, no serological evidence for SS was detected, and no response to therapy for SS was achieved. On the other hand, the symptoms are aggravated by exposure to cold in hypothyroidism, depending on impaired microcirculation ${ }^{8)}$. This is another misleading feature for the differential diagnosis between hypothyroidism and CTD. Three further possibilities can be considered to explain musculoskeletal manifestations: they may be (1) related to thyroid dysfunction, (2) secondary to CTD associated with HT, or (3) related to underlying thyroid autoimmunity ${ }^{8)}$. Our patient was diagnosed with hypothyroidism due to HT and improved with thyroid replacement therapy.

Severe hypothyroidism may be associated with highly elevated CK $(<5,000 \mathrm{U} / \mathrm{L})$ due to muscle involvement. Replacement therapy with thyroxine resulted in remarkable lowering of CK within a few weeks in our case 1 . Musculoskeletal complaints

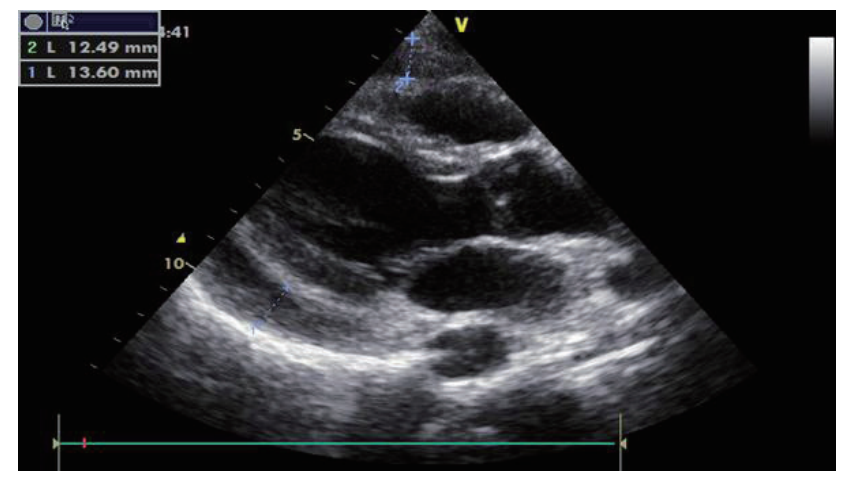

Fig. 3. Pericardial effusion exceeding $1 \mathrm{~cm}$ on echocardiography in case 3. 
and marked elevation of muscle enzymes may be a clinical manifestation of hypothyroidism; this has predominantly been described in adults ${ }^{9}$. In the literature, there were a few children and adolescents with hypothyroidism due to HT presenting musculoskeletal complaints and marked elevation of muscle enzymes ${ }^{7,10}$. Sbrocchi et al. ${ }^{11)}$ reported 3 children who had these signs and symptoms; HT was the cause of hypothyroidism in 2 of the 3 patients. All of these cases suggest that hypothyroidism is more likely responsible for the muscle complaints rather than autoimmune processes in HT. But autoimmune processes in several of the patients with HT may be associated with the skeletal muscle alterations, independently of the functional state of the thyroid gland. Clinical signs and symptoms improve with thyroxine therapy, even if the patients are euthyroid ${ }^{12)}$.

$\mathrm{PE}$ is a rare complication in children with severe hypothyroidism but can be seen in 10 and $30 \%$ of adults ${ }^{4}$. Case 3 had minimal PE, and she has Down syndrome. The incidence of hypothyroidism in patients with Down syndrome is high. A small PE can frequently be found in cases of Down syndrome with hypothyroidism. In these patients, the PE is completely resolved with thyroxin therapy without pericardiocentesis, as in our case $3^{4,13)}$

In hypothyroidism, the accumulation of fluid in the pericardial space usually occurs very slowly. Therefore, a massive PE is rare and is often associated with a severe and prolonged form of the disease ${ }^{14)}$. Case 2 was a Syrian refugee. She was admitted to the emergency department with dyspnea and altered consciousness. On echocardiography, a massive PE around the heart was found. Cardiologists performed pericardiocentesis on the patient. At admission, her thyroid function was not assessed, but it was assessed when hypotension persisted in the patient. Overt hypothyroidism was diagnosed. L-thyroxine was started. To date, four children and adolescents with hypothyroidism who have a massive PE without Down syndrome have been reported in literature ${ }^{14-16,17)}$. The cause of hypothyroidism was HT in 3 of 4 patients ${ }^{14-16)}$. In 1 of 4 patients, there was an unknown cause of hypothyroidism ${ }^{18)}$.

The most common and prominent manifestation of hypothyroidism in children is profound severe growth failure ${ }^{17}$. Two of our patients had severe growth failure without Down syndrome. Medical conditions such as renal failure and celiac disease are known causes of growth failure in children ${ }^{19}$. One of our patients was diagnosed with CTD before. But severe growth failure is not a usual manifestation at the onset of $\mathrm{CTD}^{20)}$. The presence of a PE in the patient does not explain the severe growth failure. This finding suggests that our patients had untreated prolonged hypothyroidism due to HT. Prolonged juvenile acquired hypothyroidism results in a permanent height deficit related to the duration of thyroxine deficiency before treatment ${ }^{19)}$.

In conclusion, children and adolescents with hypothyroidism due to HT have complicated clinical manifestations and individual variation and therefore can be easily misdiagnosed and mismanaged. A good history taking and a thorough physical examination facilitates the diagnosis. Growth failure is an important sign for diagnosis of hypothyroidism. In the presence of complicated manifestations, particularly associated with growth failure, primarily thyroid function tests should be evaluated in children and adolescents.

\section{Conflict of interest}

No potential conflict of interest relevant to this article was reported.

\section{References}

1. Radetti G. Clinical aspects of Hashimoto's thyroiditis. Endocr Dev 2014;26:158-70.

2. Lee HS, Hwang JS. The natural course of Hashimoto's thyroiditis in children and adolescents. J Pediatr Endocrinol Metab 2014;27:807-12.

3. Caturegli P, De Remigis A, Rose NR. Hashimoto thyroiditis: clinical and diagnostic criteria. Autoimmun Rev 2014;13:391-7.

4. Martinez-Soto T, Deal C, Stephure D, Trussell R, Boutin C, Djemli A, et al. Pericardial effusion in severe hypothyroidism in children. J Pediatr Endocrinol Metab 2010;23:1165-8.

5. Duyff RF, Van den Bosch J, Laman DM, van Loon BJ, Linssen WH. Neuromuscular findings in thyroid dysfunction: a prospective clinical and electrodiagnostic study. J Neurol Neurosurg Psychiatry 2000;68:750-5.

6. Anwar S, Gibofsky A. Musculoskeletal manifestations of thyroid disease. Rheum Dis Clin North Am 2010;36:63746.

7. Cakir M, Samanci N, Balci N, Balci MK. Musculoskeletal manifestations in patients with thyroid disease. Clin Endocrinol (Oxf) 2003;59:162-7.

8. Punzi L, Betterle C. Chronic autoimmune thyroiditis and rheumatic manifestations. Joint Bone Spine 2004;71:27583.

9. Finsterer J, Stöllberger C, Grossegger C, Kroiss A. Hypothyroid myopathy with unusually high serum creatine kinase values. Horm Res 1999;52:205-8.

10. Madariaga MG. Polymyositis-like syndrome in hypothyroidism: review of cases reported over the past twenty-five years. Thyroid 2002;12:331-6.

11. Sbrocchi AM, Chédeville G, Scuccimarri R, Duffy CM, Krishnamoorthy P. Pediatric hypothyroidism presenting with a polymyositis-like syndrome and increased creatinine: report of three cases. J Pediatr Endocrinol Metab 2008;21:89-92.

12. Villar J, Finol HJ, Torres SH, Roschman-González A. Myopathy in patients with Hashimoto's disease. Invest Clin 2015;56:33-46.

13. Werder EA, Torresani T, Navratil F, Arbenz U, Eiholzer $\mathrm{U}$, Pelet B, et al. Pericardial effusion as a sign of acquired hypothyroidism in children with Down syndrome. Eur J 
Pediatr 1993;152:397-8.

14. Gyon YH, Han HS. Massive pericardial effusion and short stature caused by autoimmune hypothyroidism in a 9-yearold girl. Ann Pediatr Endocrinol Metab 2015;20:98-101.

15. Sanda S, Newfield RS. A child with pericardial effusion and cardiac tamponade due to previously unrecognized hypothyroidism. J Natl Med Assoc 2007;99:1411-3.

16. da Silva PS, Lau AR. Massive pericardial effusion in a child: an unusual presentation of hypothyroidism. Eur J Emerg Med 2010;17:181-2.
17. Rivkees SA, Bode HH, Crawford JD. Long-term growth in juvenile acquired hypothyroidism: the failure to achieve normal adult stature. N Engl J Med 1988;318:599-602.

18. Purkait R, Prasad A, Bhadra R, Basu A. Massive pericardial effusion as the only manifestation of primary hypothyroidism. J Cardiovasc Dis Res 2013;4:248-50.

19. Taback SP, Dean HJ, Elliott E. Management of short stature. West J Med 2002;176:169-72.

20. Berard RA, Laxer RM. Pediatric mixed connective tissue disease. Curr Rheumatol Rep 2016;18:28. 